\title{
STUDIES IN CAPILLARITY.
}

II. On a Modification of the Capillati Tube Method for the Measurement of Surface Tensions.

\author{
By Allan Ferguson, M.A., D.Sc., and P. E. Dowson, M.A., \\ Department of Physics, Manchester College of Technology.
}

The determination of surface tensions by the measurement of the rise of a liquid in a capillary tube is more than ordinarily difficult. It is not easy, in the first place, to find a tube of sufficiently uniform cross-section to use with different liquids-some experimenters have spent as much as four months in searching for a uniform piece of capillary tubing. ${ }^{1}$ When this is found, the calibrating, cleaning and keeping clean of such a piece of tubing are no small matters. Nor is it easy to measure the height of ascent of the liquid, and to estimate the temperature of the meniscus with the accuracy demanded. And when we remember that, all the measurements having been made with due care, the value obtained is not $T$, but T $\cos \theta$ it becomes increasingly clear that the convenience of this widely used method is more apparent than real.

The importance of a knowledge of the temperature-coefficient of a surface tension requires special emphasis. Not only does a knowledge of this coefficient enable us to make comparisons between different liquids under comparable temperature conditions, but it also enables us to calculate the critical temperature of an unassociated liquid with considerable accuracy. For the surface tension of such a liquid is expressed very closely, from freezing point to critical temperature, by the equation

$$
\mathrm{T}=\mathrm{T}_{o}(\mathrm{I}-b \theta)^{n}
$$

where $b$ is accurately the reciprocal of the critical temperature. ${ }^{2}$ The exactness with which this equation gives the critical temperature may be judged from the figures given in Table I. below.

TABLE I.

\begin{tabular}{|c|c|c|c|c|}
\hline Substance & & $\theta_{c}\left(=\frac{I}{b}\right)$. & $\theta_{c}$ Observed. & Difference. \\
\hline $\begin{array}{l}\text { Ether } \\
\text { Benzene . } \\
\text { Methyl formate } \\
\text { Chloro-benzene } \\
\text { Methyl butyrate } \\
\text { Ethyl formate. } \\
\text { Propyl formate }\end{array}$ & 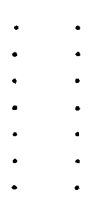 & $\begin{array}{l}194^{\circ} 0^{\circ} \\
288^{\circ} 0^{\circ} \\
213^{\circ} 0^{\circ} \\
35^{\circ} 0^{\circ} \\
281^{\circ} 0^{\circ} \\
235^{\circ} 0^{\circ} \\
265^{\circ} 0^{\circ}\end{array}$ & $\begin{array}{l}193^{\circ} 8^{\circ} \\
288^{\circ} 5^{\circ} \\
214^{\circ} 0^{\circ} \\
359^{\circ} 2^{\circ} \\
281^{\circ} 3^{\circ} \\
235^{\circ} 3^{\circ} \\
264^{\circ} 9^{\circ}\end{array}$ & $\begin{array}{l}+0.2^{\circ} \\
-0.5^{\circ} \\
-1.0^{\circ} \\
-1.2^{\circ} \\
-0.3^{\circ} \\
-0.3^{\circ} \\
+0.1^{\circ}\end{array}$ \\
\hline
\end{tabular}

It is clear, then, that a few measurements of the surface tension of an unassociated liquid at fairly widely separated temperatures will enable us

\footnotetext{
' Harkins and Brown, Four. Amer. Chem. Soc., 4I, 503 (Igrg).

2 Ferguson, Phil. Mag., Jan. I916, p. 37. 
to calculate $b$ and $n$, and will thus furnish us with a practical method for measuring its critical temperature.

But these measurements demand an accurate knowledge of the temperature of the meniscus-a quantity by no means easy to determine, demanding, as it does, fairly elaborate thermostatic arrangements. Further than that, either expense must be incurred by closing the thermostat with windows of optical glass, or time must be spent in testing such pieces of glass as may be at hand. ${ }^{1}$

The importance of surface tension measurements in modern colloidal work renders it imperative to develop a method which shall be rapid, accurate, and shall not make too heavy a demand on the instrumental equipment of a technical laboratory. It is, we think, the unanimous opinion of workers in this branch of physics that the capillary-rise method is very difficult in practice, and is the reverse of rapid.

Practically all these troubles are swept away if, instead of measuring the rise of the liquid in a narrow tube, ze force the liquid down to the lower end of a tube immersed vertically therein, and measure, on a convenient manometer, the pressure required to effect this.

Consider the advantages of such an arrangement:-

I. Calibration troubles are completely avoided. It is only necessary to measure, once for all, the bore at the end of a capillary tube of circular cross-section. This end is the position of reference for all liquids.

2. The capillary portion of the tube may be quite short, and the tube is consequently much more easily cleaned, and kept clean.

3. The thermostatic arrangements are much simplified. The liquid may be heated electrically, and temperatures taken by means of a fine thermo-couple placed quite close to the end of the capillary.

4. The use of the cathetometer is greatly facilitated. It is far easier to measure the difference of level of the surfaces of a liquid in the limbs of a pressure gauge than to measure the rise in a capillary tube. Moreover, any convenient manometer may be used-a point of importance in a laboratory where appliances are restricted. As is easily seen, if the lower end of the capillary be just touching the liquid under observation, and the same liquid be used in the manometer, the difference of level observed will be equal to the height to which the liquid will rise in the capillary tube in the ordinary capillary-rise experiment. Clearly, a gain in sensitiveness is at once obtained by using a light liquid in the manometer. But as said above, any convenient pressure gauge may be usedthe micro-manometer devised by Threlfall, the Chattock gauge, the differential liquid manometer, ${ }^{2}$ a small receptacle closed by a thin metal disk whose motion may be suitably magnified, or in the absence of these a sloping tube attached to a wide vessel and read by a millimetre scale will give satisfactory results.

The cathetometer is not even necessary to measure the amount by which the capillary is immersed in the liquid. If this distance be determined by attaching a needle to the side of the capillary it is only necessary to form and to caliper a magnified image of the capillary and needle using a good photographic lens.

5. The time of the experiment is appreciably shortened. The accurate determination of a surface tension by the ordinary method is a tedious

\footnotetext{
${ }^{1}$ Harkins and Brown, l.c., p. 504 .

2 For a description of this simple and interesting instrument, see Barton, "Introduction to the Mechanics of Fluids" (Longmans), p. I93.
} 
process, and not one to be adventured upon light-heartedly. In our own case we found that, density determinations apart, an experiment involving $3^{2}$ separate readings of the cathetometer, could be completed in about $\mathrm{I}_{2} \frac{1}{2}$ hours. (We usually made 8 determinations of the pressure, and 8 of the distance between the needle-point and the end of the capillary.) With a "naked-eye" manometer, this time could be greatly cut down.

We now pass on to consider the experimental details; a diagrammatic sketch of the apparatus is shown below in Fig. I :-

The pressure required to force the liquid to the end of the capillary is produced by gently raising or lowering the bottle $F$ by means of a rack and pinion, and the corresponding pressure is read off on the manometer
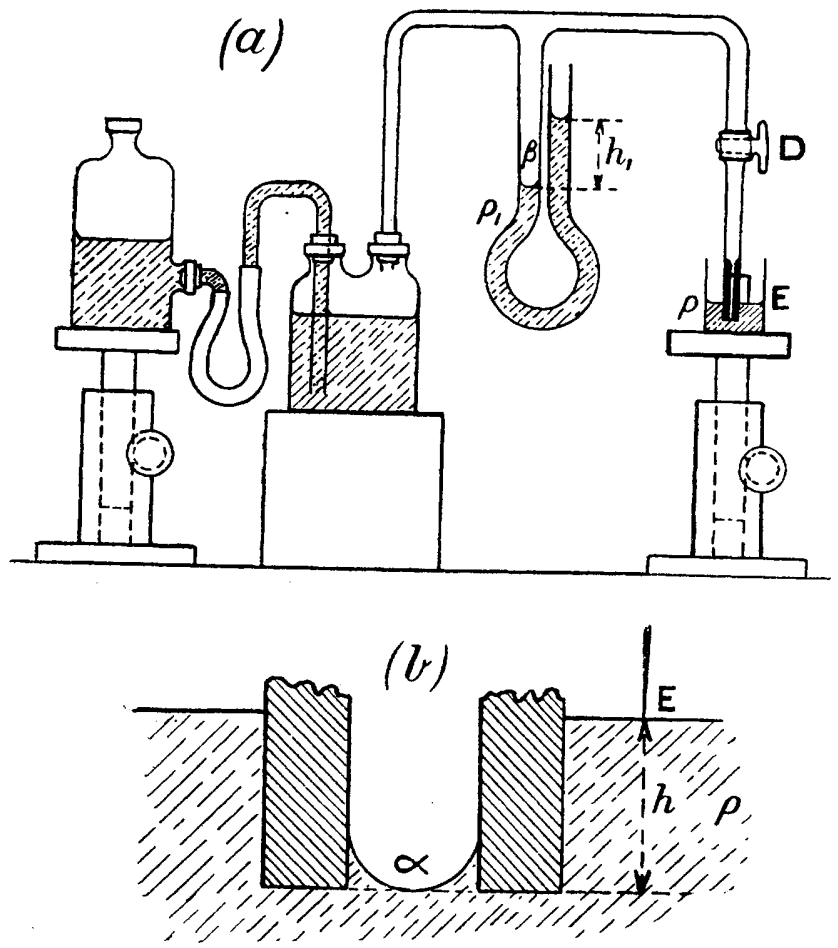

FIG. I.

C which contains a paraffin of specific gravity 0.856 at $15^{\circ}$. The manometer was read by means of a cathetometer, reading to about $\frac{1}{5000}$ th of an inch. The capillary tube was cleaned by means of sulphuric acid and bichromate, distilled water, and alcohol, and was dried by blowing through it heated and filtered air. The tube was then fused on to a wider tube just below the stopcock D. (It may here be recorded that the whole of the apparatus was in one piece-all connections being fused together, and no rubber joints admitted at any point of the apparatus. After any one determination the capillary was cut off, cleaned, and refused into position.)

The vessel containing the liquid under examination was placed on a movable table and was raised until the surface of the liquid just came into contact with a pointed index $E$ which had been previously firmly 
fastened to the capillary at a distance $h$ from the end of the tube. This adjustment could be made with great exactness by watching the image of the index point in the liquid surface. By gently raising the bottle $F$ the surface of the liquid in the tube was forced down until the lowest point of the capillary surface, as judged by the eye looking through a low power microscope, was just on a level with the bottom of the capillary tube. The exactness, or rather the consistency with which this adjustment may be made is shown by the experimental figures given later. The presence or absence of a constant error in the adjustment was roughly tested by taking readings after adjusting the pressure so that (I) the meniscus just disappeared within the tube, and (2) the meniscus just protruded from the tube; the mean of these pressure readings agreed quite satisfactorily with the "crucial" pressure.

The diameter of the capillary tube was determined by taking the mean of 40 readings (four sets at orientations increasing by $45^{\circ}$ ). The readings were taken first on the cathetometer used for reading the pressure gauge, and then on a fine dividing engine made by the Cambridge Scientific Instrument Company. ${ }^{1}$ The two determinations agreed quite satisfactorily.

The theory of the method is developed as follows:

With the notation of Fig. I the pressure at a point $\alpha$ in the air just outside the capillary surface is given by

$$
p_{a}=\mathrm{P}+g_{\rho} h+\frac{2 \mathrm{~T}}{\mathrm{R}},
$$

where $\mathrm{P}$ is the atmospheric pressure, $\mathrm{T}$ the surface tension, and $\mathrm{R}$ the radius of curvature at the vertex of the meniscus. But

giving

$$
p_{\alpha}=p_{\beta} \text { and } p_{\beta}=\mathrm{P}+g \rho_{1} h_{1}
$$

$$
\frac{2 \mathrm{~T}}{\mathrm{R}}=g\left(\rho_{1} h_{1}-\rho h\right)
$$

Now writing $a^{2} \equiv \frac{\mathrm{T}}{g \rho}$, we know that the height to which such a liquid will rise in a capillary of radius $r$ is, for a liquid of zero contact angle

$$
2 a^{2}=r h_{2}\left(\mathrm{I}+\frac{\mathrm{x}}{3} \frac{r}{h_{2}}-0 \cdot \mathrm{I} 288 \frac{r^{2}}{h_{2}^{2}}\right)
$$

But we have, accurately

$$
2 a^{2}=\mathrm{R} h_{2} \quad . \quad . \quad . \quad . \quad .
$$

and therefore comparing (iii) and (iv)

$$
\mathrm{R}=r\left(\mathrm{I}+\frac{\mathrm{r}}{3} \frac{r}{h_{2}}-0.1288 \frac{r^{2}}{h_{2}^{2}}\right)
$$

We have from (iii) to a first approximation

$$
h_{2}=\frac{2 a^{2}}{r},
$$

and to a second approximation

$$
h_{2}=\frac{2 a^{2}-\frac{1}{3} r^{2}}{r}
$$

or

$$
\frac{I}{h_{2}}=\frac{}{2 a^{2}}\left(\mathrm{I}+\frac{r^{2}}{6 a^{2}}\right) .
$$

1 With cathetometer, $d=0^{\circ} 0663 \mathrm{~cm}$. With dividing engine $d=0.06634 \mathrm{~cm}$. 
Substituting the exacter value in the second term on the R.H.S. of (v) and the more approximate value in the third term we obtain, after a little reduction

$$
\mathrm{R}=r\left(\mathrm{I}+\frac{r^{2}}{6 a^{2}}-0.0044 \frac{r^{4}}{a^{4}}\right)
$$

or, quite accurately enough for our purpose

$$
\mathrm{R}=r\left(\mathrm{I}+\frac{r^{2}}{6 a^{2}}\right)
$$

Substituting this value of $r$ in equation (ii), expanding and neglecting terms of order higher than $\frac{r^{2}}{a^{2}}$, we have finally

$$
\mathrm{T}=g_{2}^{r}\left(\rho_{1} h_{1}-\rho h\right)+g \frac{\rho r^{2}}{6}
$$

as the working equation from which to calculate the surface tension.

The cathetometer used by us was constructed to read in inches. In our case, therefore, equation (vii) takes the form

$$
\begin{aligned}
\mathrm{T} & =g r \times \mathrm{r} \cdot 27\left(\rho_{1} h_{1}-\rho h\right)+\frac{g \rho r^{2}}{6} \\
& =\mathrm{A}\left(\rho_{1} h_{1}-\rho h\right)+\frac{g \rho r^{2}}{6} .
\end{aligned}
$$

where densities are measured in $\frac{\mathrm{gm} .}{\text { c.c. }}, r$ is measured in $c m$. , and $h_{1}$ and $h$ in inches.

With one of our tubes, $r=0.033 \mathrm{I} 7 \mathrm{~cm}$, and consequently

\begin{tabular}{|c|c|c|c|c|c|}
\hline \multicolumn{3}{|c|}{ Manometer Readings. } & \multicolumn{3}{|c|}{ Readings for Immersion of Tube. } \\
\hline Open Limb. & Closed Limb. & Difference $=h_{1}$. & Needle Point. & End of Tube. & Difference $=h$ \\
\hline $\begin{array}{c}\text { ins. } \\
7 \cdot 658 \\
7 \cdot 657 \\
7 \cdot 658 \\
7 \cdot 658 \\
7 \cdot 658 \\
7 \cdot 658 \\
7 \cdot 659 \\
7 \cdot 659\end{array}$ & $\begin{array}{c}\text { ins. } \\
6 \cdot 739 \\
6 \cdot 738 \\
6 \cdot 736 \\
6.738 \\
6 \cdot 736 \\
6 \cdot 738 \\
6.736 \\
6.737\end{array}$ & $\begin{array}{c}\text { ins. } \\
0.919 \\
0.919 \\
0.922 \\
0.920 \\
0.922 \\
0.920 \\
0.923 \\
0.922\end{array}$ & $\begin{array}{c}\text { ins. } \\
2 \cdot 266 \\
2 \cdot 267 \\
2 \cdot 268 \\
2 \cdot 269 \\
2 \cdot 268 \\
2 \cdot 258 \\
2 \cdot 258 \\
2 \cdot 257\end{array}$ & $\begin{array}{l}\text { ins. } \\
2 \cdot 181 \\
2 \cdot 181 \\
2 \cdot 181 \\
2 \cdot 183 \\
2 \cdot 180 \\
2 \cdot 173 \\
2 \cdot 170 \\
2 \cdot 171\end{array}$ & $\begin{array}{l}\text { ins. } \\
0.085 \\
0.086 \\
0.087 \\
0.086 \\
0.088 \\
0.085 \\
0.088 \\
0.086\end{array}$ \\
\hline & Mean $h_{\mathrm{j}}=$ & $0.92 \mathrm{I}$ & & Mean $h=$ & 0.0864 \\
\hline
\end{tabular}

$$
\log \mathrm{A}=\mathrm{I} \cdot 6 \mathrm{I} 62 .
$$

The table immediately following gives the figures obtained in a determination of the surface tension of benzene.

TABLE II.-(BENZENE).

Hence $\rho_{1} h_{1}-\rho h=0.7882-0.0763=0.7$ I I 9 .

And from (viii)

$$
T_{15.5}=A \times 0.7119+0.16=29.58 \text { dyne- } \mathrm{cm}^{-1} \text {. }
$$


The relation between surface tension and temperature in the case of benzene is given by

$$
\begin{aligned}
\mathrm{T}_{\theta} & =\mathrm{T}_{o}(\mathrm{I}-b \theta)^{n} \\
& =\mathrm{T}_{o}(\mathrm{I}-n b \theta)
\end{aligned}
$$

for small variations in the temperature, where we may take $n=\mathbf{I} \cdot \mathbf{2}$,

TABLE III.-(TOLUENR).

\begin{tabular}{|c|c|c|c|c|c|}
\hline \multicolumn{3}{|c|}{ Manometer Readings. } & \multicolumn{3}{|c|}{ Readings for Immersion of Tube. } \\
\hline Open Limb. & Closed Limb. & Difference $=h_{1}$. & Needle Point. & End of 'rube. & Difference $=h$. \\
\hline $\begin{array}{l}\text { ins. } \\
8 \cdot 43^{2} \\
8 \cdot 43^{\circ} \\
8 \cdot 430 \\
8 \cdot 43^{\circ} \\
8 \cdot 430 \\
8 \cdot 428 \\
8 \cdot 429 \\
8 \cdot 443\end{array}$ & $\begin{array}{c}\text { ins. } \\
7 \cdot 561 \\
7 \cdot 562 \\
7 \cdot 563 \\
7 \cdot 564 \\
7 \cdot 565 \\
7 \cdot 566 \\
7 \cdot 567 \\
7 \cdot 579\end{array}$ & $\begin{array}{c}\text { ins. } \\
0.871 \\
0.868 \\
0.867 \\
0.866 \\
0.865 \\
0.862 \\
0.862 \\
0.864\end{array}$ & $\begin{array}{c}\text { ins. } \\
2 \cdot 636 \\
2 \cdot 63^{6} \\
2 \cdot 634 \\
2 \cdot 635 \\
2 \cdot 637 \\
2 \cdot 635 \\
2 \cdot 636 \\
2 \cdot 636\end{array}$ & $\begin{array}{l}\text { ins. } \\
2 \cdot 595 \\
2.594 \\
2.596 \\
2 \cdot 595 \\
2.597 \\
2 \cdot 595 \\
2.597 \\
2 \cdot 594\end{array}$ & $\begin{array}{c}\text { ins. } \\
0.041 \\
0.042 \\
0.038 \\
0.040 \\
0.040 \\
0.040 \\
0.039 \\
0.042\end{array}$ \\
\hline & Mean $h_{1}=$ & 0.8656 & & Mean $h=$ & 0.0402 \\
\hline
\end{tabular}

$$
\theta=150^{\circ} \mathrm{C} . \quad \rho_{1}=0.8559 . \quad \rho=0.8715 . \quad \log \mathrm{A}=\mathrm{r} \cdot 6 \mathrm{r} 62 .
$$

$$
\begin{aligned}
& \rho_{1} h_{1}-\rho h=0.7400-0.0350=0.7050 . \\
& \mathrm{T}_{15}=\mathrm{A} \times 0.7050+0.16=29.13+0.16=29.29 \text { dyne-cm. }{ }^{-1} .
\end{aligned}
$$

$b=\frac{\mathrm{I}}{288}$, and consequently $n b=0.00420$. Hence, we may write, very approximately

$$
\mathrm{T}_{15}=\mathrm{T}_{6}\left\{\mathrm{r}-n b\left(\mathrm{I}_{5}-\theta\right)\right\} .
$$

giving a change in the surface tension of about $0^{\circ} 1_{4}$ dynes per $\mathrm{cm}$. per degree.

From the above experiment, we have, with this value of the temperature coefficient

$$
\mathrm{T}_{15}=29 \cdot 65 \text { dyne-cm. }{ }^{-1} \text {. }
$$

In Table III. above is given a similar set of readings obtained with toluene.

There is no need to give details of all the readings for the remaining experiments; Table IV. on page 390 gives a conspectus of the results obtained.

The production of authoritative figures for the surface tensions of these compounds forms no essential part of this paper; our main object is to show that the very simple modification proposed removes the chief technical difficulties that beset the capillary-rise method, and that the method does effect this object is almost a priori evident. But the discussion of one or two points connected with the above figures will, we think, be of use.

Our experience of benzene has convinced us that this liquid is, for a standard liquid, more than a little treacherous. The six values for $T_{15}$ given above represent but a small fraction of our experimental figures, which, however, group themselves into two classes-one set giving a value

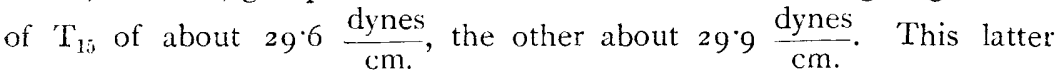


TABLE IV.

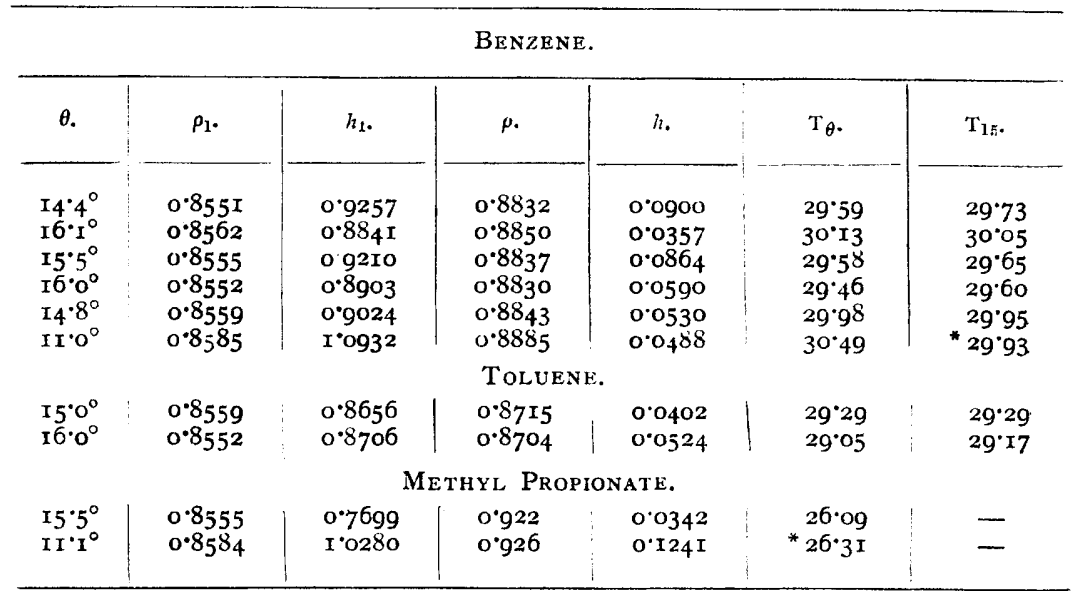

(The starred results were obtained using a new tube for which $r=0^{\circ} 02724 \mathrm{~cm}$., and therefore $\log A=I^{\circ} 5307$. )

figure is the value which we generally obtained after performing all the usual rites associated with the purification of benzene. It was only when, in addition, we made several fractional crystallisations of the specimen, and then immediately determined the surface tension, that the lower figures were obtained. On allowing the benzene to stand for a few days its surface tension reverted to the higher value.

Whatever be the apparatus employed for the determination of surface tensions, it is clearly advantageous to have at hand a standard liquid which can be used to test the apparatus. We ourselves feel that benzene is far from being the ideal liquid; for it in several respects falls short of such a standard, which should
(i) be easily prepared;
(ii) be easily purified ;
(iii) be non-hygroscopic ;
(iv) not be liable (like water) to surface contamination ;
(v) not attack glass.

In Table IV. above, the first, third, and fifth results were in each case taken immediately after three fractional crystallisations of different specimens of purified benzene. The mean of these gives

$$
T_{15}=29 \cdot 66 \frac{\text { dynes }}{\mathrm{cm} .} \text {. }
$$

In Table $\mathrm{V}$, on followiug page are given a few of the results obtained by other experimenters.

It seems then that, with the exception of Renard and Guye's value, ${ }^{1}$ the value we have obtained is in very close agreement with the values given by the ordinary technique of the capillary rise method. The latest and most careful experiments are those of Harkins and Brown, and of Richards and Coombs, and our mean value agrees with theirs to about I part in 500 .

These experiments were carried out in the Physical Laboratories of

${ }^{1}$ Ramsay and Aston's value is for the surface tension of benzene in contact with its saturated vapour. 
the Manchester College of Technology, and it is our pleasant duty to thank Professor Gee or the assistance which he has given us, and for the facilities which he has placed at our disposal.

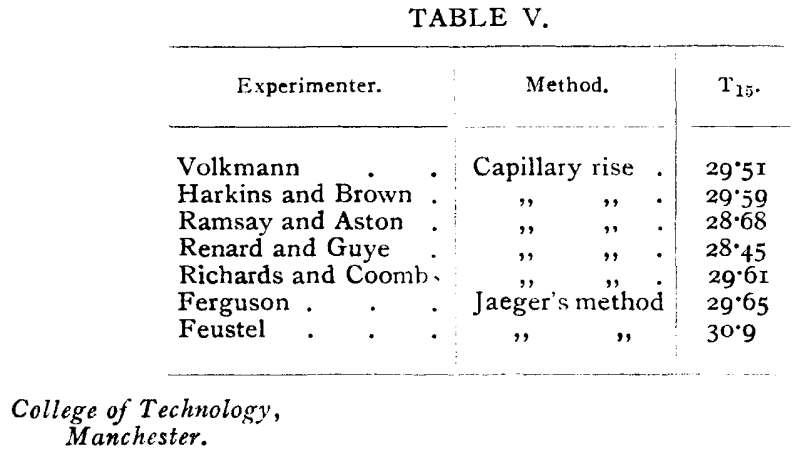

December, 1920 .

Dr. F. C. Thompson, D.Met., B.Sc., contributed to the discussion the following note on "The Interfacial Tension Between Carbide of Iron $\left(\mathrm{Fe}_{3} \mathrm{C}\right)$ and Iron".

The probability that surface energy plays an important rôle in determining the mechanical properties of metals has received increasing attention since $19^{1} 5$, when a paper was read before the Faraday Society ${ }^{1}$ in which the suggestion was made that such phenomena at the crystalline boundaries might be a dominating factor in determining the elastic limit of the metal.

No attempt, however, appears to have been made to determine in the case of solid metals the magnitude of such effects. It is possible in certain cases, however, to utilise the method of Ostwald and Hulett which has already yielded interesting results in the case of the solid sulphates of calcium and barium. The measurement of the interfacial tension between $\mathrm{Fe}_{8} \mathrm{C}$ and iron was made by determining from the electrical resistance of the samples of the same steel hardened together, but tempered at $500^{\circ} \mathrm{C}$. and $650^{\circ} \mathrm{C}$. respectively, the influence of the size of the carbide globules on the solubility of cementite in iron.

The steel used had the following analysis :-

$\begin{array}{ccccc}C \text { per cent. } & \text { Si per cent. } & \text { Mn per cent. } & \text { S per cent. } & \text { P per cent. } \\ 0.69 & 0.144 & 0.68 & 0.049 & 0.019\end{array}$

and was received in the form of wire about $\frac{7}{10}$ th of an inch in diameter. A length of 27 inches was heated to $780^{\circ} \mathrm{C}$., quenched in water, and then tempered at $500^{\circ} \mathrm{C}$. As a result of this treatment the material possessed a structure consisting of very fine globules of $\mathrm{Fe}_{3} \mathrm{C}$ embedded in a matrix of more or less carbon free iron, i.e. sorbite. A second piece was reheated to $650^{\circ} \mathrm{C}$. for several hours and cooled in air, and a structure of a similar type to the previous one but with much coarser globules was induced.

After having been well cleaned with emery cloth to remove scale and any decarburised surface and then carefully straightened the specific

\footnotetext{
${ }^{1}$ Trans. Faraday Soc., Igr5, xi., ro4.
} 
resistance of each material was measured on a Kelvin double-bridge apparatus which has been checked against a standard resistance of 0.01 ohm. The fall of potential along a length of $50 \mathrm{cms}$. was measured, the exact point of balance being obtained by noting the deflections produced by contacts very slightly displaced on each side of the point. The diameter of each wire was very carefully measured at five points by a micrometer sensitive to $0.0000 \mathrm{I}$ ins.

The values of the specific resistances at $10^{\circ} \mathrm{C}$. are :-

(a) Quenched and tempered at $500^{\circ} \mathrm{C}$. I7.873 microhms per $\mathrm{cm}$. cube.

(b) Annealed at $650^{\circ} \mathrm{C}$. . . . r $6.732 \quad, \quad,,$, ,

Benedicks has shown ${ }^{1}$ that the presence of $I$ per cent. of carbon in solution in iron raises the resistivity by 26.8 microhms per $\mathrm{cm}$. cube. If the difference in the resistivities in the case examined is due to the increased solubility of the carbide due to the fineness of the division of the globules, this difference of solubility must be 0.042 per cent. carbon.

It should be remembered that this represents the increased solubility at $500^{\circ} \mathrm{C}$. at which temperature the structure was produced. It is difficult to say exactly what is the normal solubility of carbon in iron at this temperature, but it is unlikely that it will exceed 0.02 per cent., and by using this value as a basis for the calculations a minimum value of the interfacial tension will be obtained.

The measurement of the size of the particles was a matter of difficulty and is certainly the most inexact portion of the work. The structure magnified 1500 diameters, a $2 \mathrm{~mm}$. objective of N.A. I.35 being used, was projected on to a glass screen and the diameter of particles measured. The result for the smaller globules was of the order of $0.0000 \mathrm{I} \mathrm{cms}$.

The formula used ${ }^{2}$ was :-

$$
\mathrm{R} \theta \log _{\mathrm{e}} \frac{\lambda^{\prime}}{\lambda}=\frac{2 \sigma}{\rho a}, \text { where }
$$

$\lambda^{\prime}$ is the solubility of carbon in iron where the globules have a radius $a$,

$\lambda$ is the solubility in the case of large masses,

$\sigma$ is the interfacial tension of $\mathrm{Fe}_{3} \mathrm{C}$ against iron, and

$\rho$ is the density of cementite.

In the case of the slightly nickeliferous meteoric mineral Cohenite $\rho$ is $7 \cdot 24$.

Thus :-

Where

$$
8.5 \times 10^{-4} \times 773 \times 2.3 \log _{10} \frac{0.062}{0.02}=\frac{2 \sigma}{7.24 \times 10^{-6} \times 5}
$$

$$
\sigma=\mathrm{r} 35^{\circ} \text { dynes per } \mathrm{cm} \text {. }
$$

This result is of the same order as the surface tensions of solid barium and calcium sulphates. 